\title{
Research Notes
}

\section{DIFFERENTIAL DIAGNOSIS OF INFECTION BY FASCIOLA HEPATICA AND COTYLOPHORON COTYLOPHORUM IN CATTLE AND SNAIL HOSTS ${ }^{1,2}$}

Fasciola hepatica is the common liver-fluke of cattle. Cotylophoron cotylophorum is the rumen-fluke of cattle. Both parasitic species occur in Puerto Rico ${ }^{3}$. A recent survey by laboratory fecal examination for bovine fascioliasis in the Dorado area revealed that cattle in 17 ( 89 percent) on the 19 farms studied have liver-fluke and 18 (94 percent) have rumen-fluke $\mathrm{e}^{4}$.

Both flukes in Puerto Rico have eattle as their final host. Both have the same species of snails, $L$. cubensis and $L$. columella, as intermediate hosts.

Scme of the improved techniques for laboratory and field diagnoses of fluke ova in the feces recommend staining 1 ith jodine ( 7 or 15 percent) to facilitate diagnosis ${ }^{5,6}$. When ova of both $F$. hepatica and $C$. colylophorum concur in fees, iodine staining of the sample can hinder rapid differential identification. A $0 . \overline{5}$ percent solution of methyl green is highly recommended ${ }^{7}$ for this purpose as it stains fecal debris but not fluke eggs; those of the liver-fluke appear in their natural amber color while those of the rumen-fluke appear in their silver color. Liver-fluke ova are elliptical and have fine granules. Those of the rumen-fluke are ovoid with slight attenuation at the opercular end and have coarse granules.

Differentiation of the larval stages of the liver-fluke and the rumen-fluke while still in the snail is relatively easy. $F$. hepatica and $C$. cotylophorum (ggs were incubated following the method described by Gómes et al ${ }^{8}$.

Fasciola hepatica miracidium have an "cye spot." Those of $C$. cotylophorum have none.

${ }^{1}$ Manuscript submitted to the Editorial Board December 5, 1973.

$2 \mathrm{Mr}$. Félix Liard is herewith credited for the photographs.

${ }^{3}$ Van Volkenberg, H. L., An Annotated Check List of the Parasites of Animals in Pucrto Rico, P.R. Experimental Station, USI)A Mayagüez, Puerto Rico Cir. No. 22, Washington, J. C. p. 5, Jan. 1939.

+ De León, D., litchie, L. S., and Chiriboga, J., Fascioliasis in Dairy Cattle in lío Plata Basin of the Dorado Area, P.R., J. Agr. Univ. P. R. 56(1): 82-92, 1972.

"Dennis, W. R., Stone, W. M., and Swanson, L. E., A New Laboratory and Field Diagnostic Test for Fluke Ova in Feees, J. Am. Vet. Med. Assoc. 122: 47-50, Jan. 1954.

${ }^{6}$ Rivera-Anaya, J. D), and Martínez de Jesús, J., An Improved Technique for Microscopic Diagnosis of Liver-Fluke Infection in Cattle, J. Agr. Univ. P.R. 35(3): 98-9, 1951 .

: Ueno, II., Private Communication, 1971.

" (iómez, P., Velarde, A., Chiriboga, J., and de León, I)., A Simple Method of Mass Production of Fasciola hepatica miracidia, J. Agr. Univ. P.R. 57(1): 87-88, Jan. 1973. 

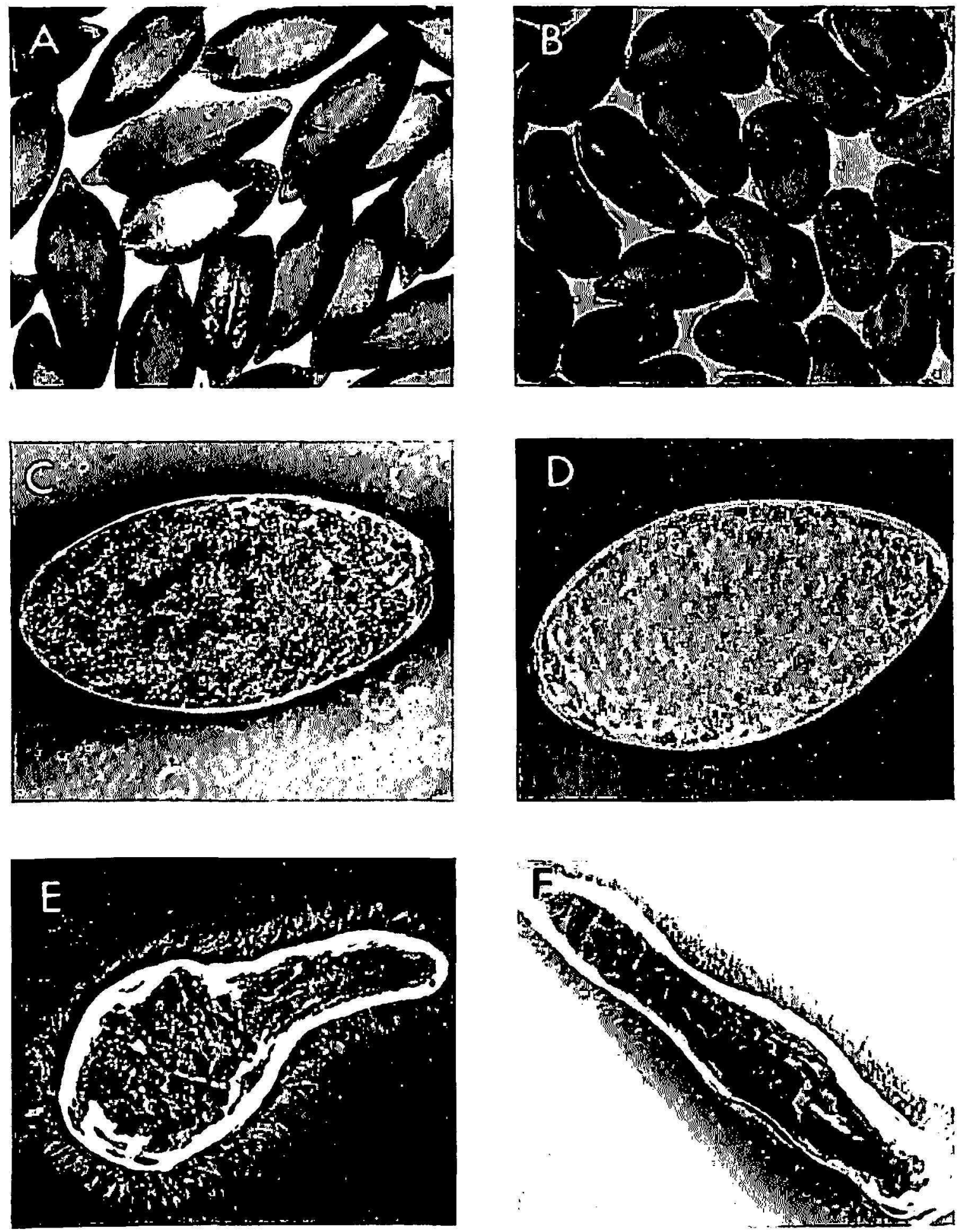

Fig. 1.-Differential diagnosis of Fasciola hepatica and Colylophoron colylophorum infection in cattle and the snail hosts. A, Adult, F. hepatica, $\times 1$; B, Adult, C. colylophorum, $\times 3$; C, Egg, F. hepatica, $\times 500 ; \mathrm{D}, \mathrm{Egg}, C$. colylophorum, $\times 550$, E, Miracidium, F. hepatica, $\times 600 ; \mathrm{F}$, Miracidium, C. colylophorum, $\times 500$. 

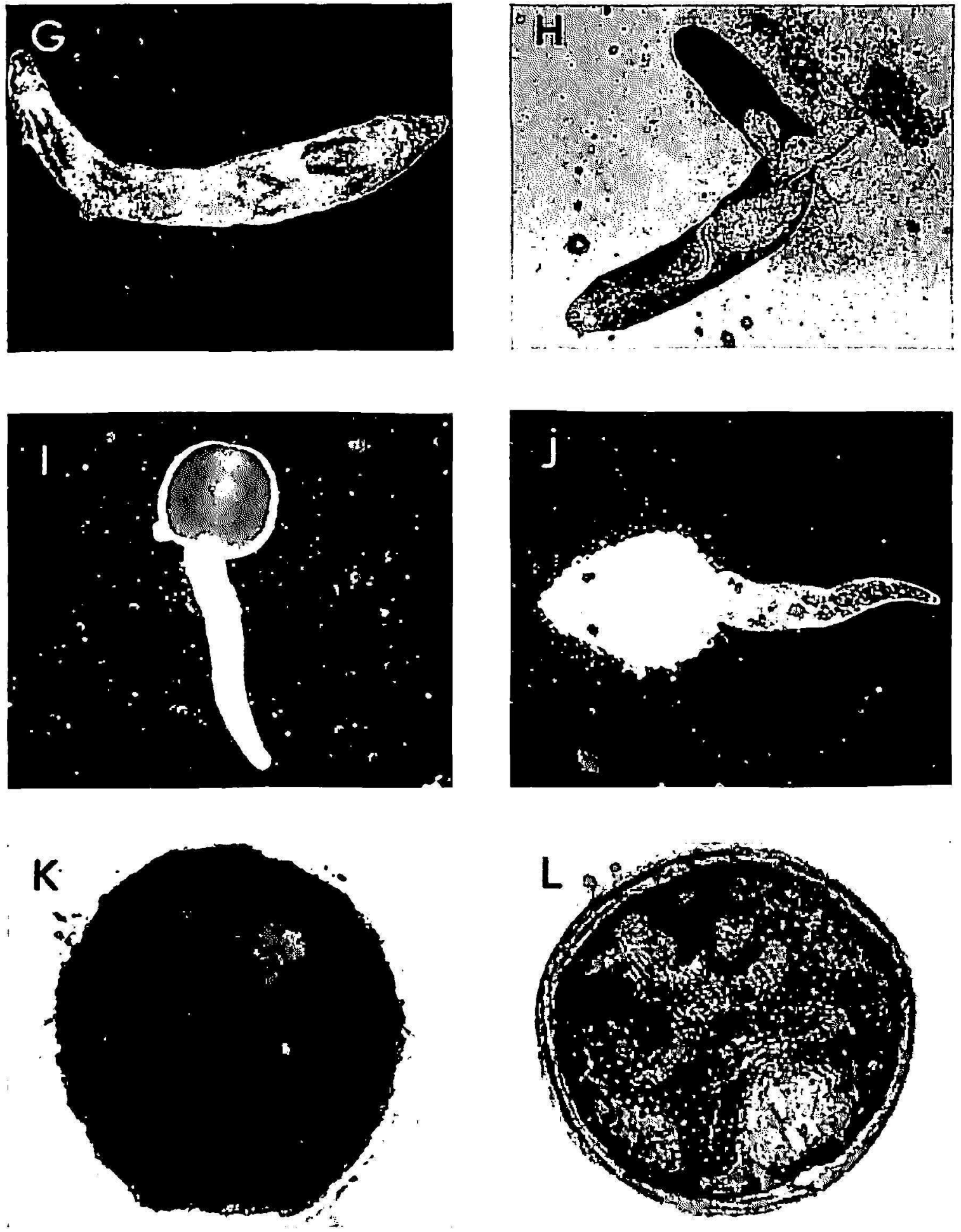

Fici. 1. Continued. (i, Redia, $F$.hepalica, $\times 50$; H, Redia, C. colylophorum, $\times 100$; I, Cercaria, $F$. hepalica, $\times 100$; J, Cercaria, $C$. colylophorum $\times 200 ; \mathrm{K}$, Metacerearia, F. hepalica, $\times 100$; L, Metacercaria, C. cotylophorum, $\times 200$. 
Snails were crushed gently between two slides 18 and 32 days after infection with miracidia and the "liver" separated from other organs and shell fragments. The "liver" then was pressed between a glass slide and a cover-slip, and examined under a compound microscope.

Rediae of both $F$. hepatica and $C$. colylophorum have circular thickening behind the level of the pharynx and a pair of blunt processes at the beginning of the posterior quarter. $F$. hepalica rediae are characterized by the presence of well-pronounced cystogenous glands in the developing cercariae; those of $C$. cotylophorum by the presence of "eye-spots".

Cercaria of $F$. hepatica have well-developed cystogenous glands; those of $C$. colylophorum have "eye-spots".

Metacercaria of $F$. hepatica are heavily covered with muco-protein substance while those of $C$. cotylophorum are not.

D. de León

Agricullural Experiment Station

J. Chiriboga

D. Parra

Puerto Rico Nuclear Center

II. Llavona

Puerto Rico Department of Agriculture 